\title{
Heat Transfer Model of a Structural Element for the Transformation of Housing Sustainability
}

\author{
Alarcón-Montelongo Ivan S. ${ }^{1}$, Aranda-Jiménez Yolanda G. ${ }^{1}$, Fernández- Zayas José L. ${ }^{2}$, \\ Sánchez-Medrano María T. ${ }^{1}$, Suárez-Domínguez Edgardo J. 3,*, Elena Izquierdo-Kulich. ${ }^{4}$ \\ ${ }^{1}$ Faculty of Architecture, Design, and Urbanism, University Autonomous of Tamaulipas, Circuito Universitario S/N, \\ Centro Universitario Sur, Tampico, Tamaulipas, México \\ ${ }^{2}$ Engineering Institute, UNAM, Circuito Interior S/N. Ciudad Universitaria, Ciudad de México, México \\ ${ }^{3}$ FADU Research Centre, Autonomous University of Tamaulipas, Circuito Universitario S/N, Centro Universitario del Sur, \\ Tampico, Tamaulipas, México \\ ${ }^{4}$ Department of Physical-Chemistry, Faculty of Chemistry, University of Havana, Zapata Street S/N. La Habana, Cuba
}

Received May 15, 2020; Revised June 22, 2020; Accepted July 4, 2020

Copyright $\mathrm{C} 2020$ by authors, all rights reserved. Authors agree that this article remains permanently open access under the terms of the Creative Commons Attribution License 4.0 International License

\begin{abstract}
Nowadays, it is common to find heat transfer systems inside buildings. In the present work, a heat transfer system applied to a structural element of a building is proposed, which is produced with a system embedded inside the wall from the internal transport of the liquid that allows increasing or decreasing the interior temperature. For this, a mathematical model developed from a steady-state, one-dimensional energy balance was analytically solved. The system was applied in a circadian way with the data applicable to maximum and minimum temperatures in the city of Monterrey, Nuevo León. Experimentally, the thermal properties of the proposed material were obtained and a wall section was developed with the heat transfer system. An increase in thermal resistance is obtained that allows reducing the temperature changes on the interior face of the wall. The structural element presents thermal resistance values that increase while maintaining the fluid inside the wall. The system justifies the use of fluid within the vertical element that can promote comfort. Using this system would reduce energy consumption by up to $60 \%$ compared to a traditional cooling system. The objective of this work was to obtain a mathematical model that approximately describes the behavior of the interior temperature of the wall as a function of the exterior temperature and the flow and temperature of the cooling water, to evaluate the energy efficiency of the heat exchanger.
\end{abstract}

Keywords Heat Transfer in Walls, Increase in Thermal Delay, Energy Saving

\section{Introduction}

Currently, traditional homes have a greater number of equipment such as refrigerators, televisions, washing machines, and air conditioners with low energy efficiency, in rural areas they present the same situation with less consumption due to the population index [1]. Furthermore, it is estimated that the number of homes will reach almost 50 million in 2030 [2], which may increase the presence of heat islands [3] and this makes us think of the importance of implement energy efficiency measures in buildings, both in new homes and in existing ones. Energy consumption can be reduced from sustainable techniques such as construction systems and systems in rural housing [4].

It is important to evaluate heat transfer processes over time, mainly from the perspective of envelopes [5], since they are related to comfort processes leading to a bioclimatic design [6]. Some processes have focused on the weighting of the thermal balance through a material [7]. Structural elements such as load-bearing walls or slabs found on the surface faces of buildings can receive significant amounts of solar radiation; When the material is similar to concrete, the heat transfer increases substantially compared to others that contain or are entirely made with insulating coatings [8].

Some heat transfer systems can be designed from passive arrangements [9,10], or different elaboration systems of elements can be used from a hollow conformation that decreases the thermal transmittance [11]. Although cooling processes can be designed by daily cycles [12], together, modeling of heat transfer systems in hollow concrete block walls is well known [13] and passive cooling systems have been applied in slabs such as green roofs [14] as well as irrigation systems in slabs that decrease the temperature. This can positively impact the reduction of energy use and therefore the impact on the environment [15]. 
Exterior wall temperature $T_{22}$

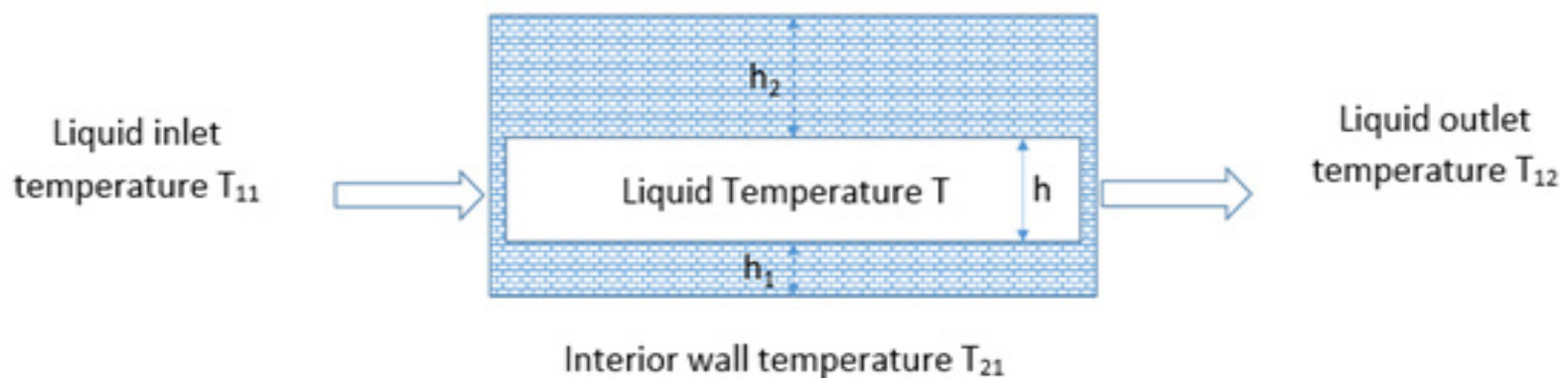

Figure 1. Cross-section of a wall with a space inside it through which a liquid flows

\section{Method}

For the model design, there is a wall within which there is a space through which water flows, which exchanges heat with the solid wall, in such a way that the interior part of the wall has a lower temperature than the exterior, which is in contact with the environment (Figure 1).

The model obtained was evaluated for extreme cases presenting the possible results. Once a constant temperature was obtained, the system was compared against a traditional one based on air cooling and $1000 \mathrm{~W}$ of power in terms of energy consumption.

\section{Obtaining the model}

For model obtaining, we applied the law of conservation of energy from a macroscopic balance in steady-state, in such a way that for the temperature of the cooling water inside the wall, the time differential equation:

$$
\begin{aligned}
\rho_{1} A h \eta_{1} \frac{d T}{d t} & =Q_{1} \rho_{1} \eta_{1} T_{11}-Q_{1} \rho_{1} \eta_{1} T_{12}+k_{2} \frac{A}{h_{2}}\left(T_{22}-T\right) \\
T(0) & =T_{0}
\end{aligned}
$$

while for the temperature on the inside of the wall it is written:

$$
\begin{aligned}
\rho_{2}\left(A h_{1}\right) \eta_{2} \frac{d T_{21}}{d t} & =k_{2} A \frac{\left(T-T_{21}\right)}{h_{1}} \\
T_{21}(0) & =T_{21,0}
\end{aligned}
$$

In equations (1) and (2), T11 and T12 are the inlet and outlet temperature of the cooling water, respectively, T21 and T22 are the interior and exterior wall temperature, respectively, $\mathrm{T}$ the water flow temperature of cooling inside the wall ( $\mathrm{K}$ or $0 \mathrm{C}), \rho 1$ and $\rho 2(\mathrm{~kg} / \mathrm{m} 3)$ represent the density of water and the solid that forms the wall, respectively, $\eta 1$ and $\eta 2(\mathrm{~J} /(\mathrm{kg} . \mathrm{K}))$ are the heat capacity per unit mass of water and solid, A (m2) is the total area of the wall, $h(m)$ is the thickness of the section through which the water flows, $\mathrm{h} 1 \mathrm{~m}$ ) the thickness of the section of the wall that is in contact with the interior of the room and $\mathrm{h} 2(\mathrm{~m})$ the thickness of the wall that is in contact with the outside, $\mathrm{k} 2(\mathrm{~W} /(\mathrm{mK}))$ is the coefficient of thermal conductivity of the solid material, Q1 (m3/h) is the flow of cooling water and $\mathrm{t}(\mathrm{h})$ is time.

For differential equations, the temperature of the water inside the wall is considered to be equal to the outlet temperature:

$$
T=T_{12}
$$

such that the time differential equations (1) and (2) are written in the form:

$$
\begin{gathered}
\tau_{1} \frac{d T_{12}}{d t}+T_{12}=\frac{1}{\phi+1} T_{22}+\frac{\phi}{\phi+1} T_{11} \\
\tau_{2} \frac{d T_{21}}{d t}+T_{21}=T_{12}
\end{gathered}
$$

where:

$$
\phi=\frac{\eta_{1} \rho_{1} Q_{1} h_{2}}{A k_{2}}
$$

is a parameter that is related to the final variation of the leaving water temperature concerning the variation of the entering water temperature, and the time constants (h):

$$
\begin{gathered}
\tau_{1}=\frac{A h}{Q_{1}}\left(\frac{\phi}{1+\phi}\right) \\
\tau_{2}=\left(\phi \frac{\eta_{2} \rho_{2}}{\eta_{1} \rho_{1}} \frac{A}{Q_{1}} \frac{h_{1}^{2}}{h_{2}}\right)
\end{gathered}
$$

they are related to the rate of the change of the interior wall temperature and the water outlet temperature when a change in the exterior temperature occurs, as will be seen later.

In steady-state, the temporal derivative that appears in equations (4) and (5) becomes equal to zero, in such a way that:

$$
\begin{aligned}
& T_{12}=\frac{1}{\phi+1} T_{22}+\frac{\phi}{\phi+1} T_{11} \\
& T_{21}=T_{12}=\frac{1}{\phi+1} T_{22}+\frac{\phi}{\phi+1} T_{11}
\end{aligned}
$$

and, therefore, the interior temperature of the wall can be written as a function of the exterior temperature and the inlet temperature of the water: 


$$
T_{21}=\frac{1}{\phi+1} T_{22}+\frac{\phi}{\phi+1} T_{11}
$$

To find the non-steady-state behavior define the deviation variable $u$, which represents the difference between the value of the variable in the non-steady state and the value of the variable in the initial steady state, such that:

$$
\begin{gathered}
u_{12}=T_{12}-T_{12, s}: u_{11}=T_{11}-T_{11, s} \\
u_{21}=T_{21}-T_{21, s}: u_{22}=T_{22}-T_{22, s}
\end{gathered}
$$

such that the differential equations (4) and (5) are rewritten as:

$$
\begin{gathered}
\tau_{1} \frac{d u_{12}}{d t}+u_{12}=\frac{1}{\phi+1} u_{22}+\frac{\phi}{\phi+1} u_{11} \\
u_{12}(0)=0 \\
\tau_{2} \frac{d u_{21}}{d t}+u_{21}=u_{12} \\
u_{21}(0)=0
\end{gathered}
$$

To analyze the dynamic behavior of the system and its capacity to maintain the interior temperature within a range of values that guarantee adequate room comfort, the behavior of the interior temperature of the wall will be analyzed when there is a change in the outdoor temperature keeping the flow and temperature of the cooling water constant, such that:

$$
\begin{gathered}
u_{11}=0 \\
\begin{array}{r}
\text { Applying the inverse of the Lapt } \\
\text { substituting the deviation variable: }
\end{array} \\
T_{21}=\frac{B\left(1-w \tau_{1} \tau_{2}\right) \sin (t w)-\cos (t w)}{(\phi+1)\left(w^{2} \tau_{1}^{2}+1\right)\left(w^{2} \tau_{2}^{2}+1\right)}+\frac{\tau_{2}^{2} w B \exp \left(-\frac{t}{\tau_{2}}\right)}{(\phi+1)\left(w^{2} \tau_{2}^{2}+1\right)\left(\tau_{2}-\tau_{1}\right)}-\frac{B \tau_{1}^{2} w^{2} \exp \left(-\frac{t}{\tau_{1}}\right)}{(\phi+1)\left(w^{2} \tau_{1}^{2}+1\right)\left(\tau_{2}-\tau_{1}\right)}+T_{21, s}
\end{gathered}
$$

From this consideration and applying the Laplace transform the differential equations (14) and (15) are written as a system of algebraic equations:

$$
\begin{aligned}
& \tau_{1} s U_{12}(s)+U_{12}(s)=\frac{1}{\phi+1} U_{22}(s) \\
& \tau_{2} s U_{21}(s)+U_{21}(s)=U_{12}(s)
\end{aligned}
$$

Where $U_{k j}(s)$ represents the transform of the deviation variable $u_{k j}$. From (17) and combining appropriately we obtain:

$$
u_{21}(s)=u_{22}(s) \frac{1}{(\phi+1)} \frac{1}{\left(s \tau_{2}+1\right)\left(s \tau_{1}+1\right)}
$$

For a disturbance in the external temperature step jump type of magnitude B (0C) we obtain:

$$
u_{21}(s)=\frac{B}{s} \frac{1}{(\phi+1)} \frac{1}{\left(s \tau_{2}+1\right)\left(s \tau_{1}+1\right)}
$$

Applying the inverse of the Laplace transform and substituting the deviation variable, we obtain:

$$
T_{21}(t)=\frac{B}{\phi+1}-\frac{B \tau_{1} \exp \left(-\frac{t}{\tau_{1}}\right)}{\left(\tau_{1}-\tau_{2}\right)(1+\phi)}+\frac{B \tau_{2} \exp \left(-\frac{t}{\tau_{2}}\right)}{\left(\tau_{1}-\tau_{2}\right)(1+\phi)}+T_{21, s}
$$

while for a sinusoidal disturbance of amplitude B (0C) and frequency w equation (18) is written:

$$
u_{21}(s)=B \frac{w}{s^{2}+w^{2}} \frac{1}{(\phi+1)} \frac{1}{\left(s \tau_{2}+1\right)\left(s \tau_{1}+1\right)}
$$

Applying the inverse of the Laplace transform and 


\section{Results and Discussion}

In previous works [16, 17], models based on the phenomenological conservation of energy and the equation of change for temperature (ref bird) have been proposed and validated, which have allowed the temporal behaviors of the temperature profiles to be established. Generated on the walls of the rooms. Following the same reasoning, a new model was developed that considers the energy conservation equations in non-stationary systems considering the average temperature values established in the different sections of a wall inside which a stream of cooling water flows aim to maintain the comfort of the room in markedly hot climates. The main purpose of this model is to theoretically evaluate the feasibility of establishing this type of air conditioning system.

In order to analyze the predictions of the mathematical model, a concrete block wall and a dumped earth wall are considered, a construction system similar to the wall, with the analyzed water cooling system. We obtained physical properties from measurements of both the block walls and the prototype existing in the FADU UAT of poured earth and the geometric characteristics of the system, as well as the required temperature difference on both sides of the wall, defined as outside temperature minus inside temperature.

Table 1. Physical properties of materials and geometric characteristics of the wall

\begin{tabular}{|c|c|c|}
\hline Properties & Masonry & Water \\
\hline Density $\mathrm{kg} / \mathrm{m} 3$ & 1700 & 1000 \\
\hline Heat Capacity J/kg.K & 837 & 4178 \\
\hline Thermal conductivity W/m.K & 0.658 & 0.615 \\
\hline Interior wall thickness $\mathrm{m}$ & \multicolumn{2}{|c|}{0.05} \\
\hline Exterior wall thickness $\mathrm{m}$ & \multicolumn{2}{|c|}{0.07} \\
\hline $\begin{array}{l}\text { Thickness of the area where the water } \\
\text { flows } \mathrm{m}\end{array}$ & \multicolumn{2}{|c|}{0.04} \\
\hline Wall area $\mathrm{m} 2$ & \multicolumn{2}{|c|}{8} \\
\hline Inlet water temperature $0 \mathrm{C}$ & \multicolumn{2}{|c|}{20} \\
\hline $\begin{array}{c}\text { Required temperature difference on the } \\
\text { wall } 0 \mathrm{C}\end{array}$ & \multicolumn{2}{|c|}{5} \\
\hline Required interior temperature $0 \mathrm{C}$ & \multicolumn{2}{|c|}{25} \\
\hline
\end{tabular}

From equation (11) it is obtained that the required value of $\varphi$ is given by:

$$
\phi_{\text {req }}=\frac{T_{22}-T_{21}}{T_{21}-T_{11}}=\frac{5}{25-20}=1
$$

hence, the required flow value is obtained from equation (6):

$$
Q_{1}=\frac{A \phi_{\text {req }} k_{2}}{\eta_{1} \rho_{1} h_{2}}=\frac{8 \mathrm{~m}^{2}(1) 0.658 \frac{\mathrm{w}}{\mathrm{mK}}}{4178 \frac{\mathrm{J}}{\mathrm{kgK}} 997 \frac{\mathrm{kg}}{\mathrm{m}^{3}} 0.07 \mathrm{~m}}=0.06 \frac{\mathrm{m}^{3}}{\mathrm{~h}}
$$

From equations (7) and (8) we obtain:

$$
\begin{gathered}
\tau_{1}=\frac{A h}{Q_{1}}\left(\frac{\phi}{1+\phi}\right)=\frac{8 \mathrm{~m}^{2} 0.04 \mathrm{~m}}{0.06 \frac{\mathrm{m}^{3}}{\mathrm{~h}}}\left(\frac{1}{1+1}\right)=2.6667 \mathrm{~h} \\
\tau_{2}=\left(\phi \frac{\eta_{2} \rho_{2}}{\eta_{1} \rho_{1}} \frac{A}{Q_{1}} \frac{h_{1}^{2}}{h_{2}}\right)=\left((1) \frac{837 \frac{\mathrm{J}}{\mathrm{kgK}} 1700 \frac{\mathrm{kg}}{\mathrm{m}^{3}}}{4178 \frac{\mathrm{J}}{\mathrm{kgK}} 997 \frac{\mathrm{kg}}{\mathrm{m}^{3}}} \frac{8 \mathrm{~m}^{2}}{0.06 \frac{\mathrm{m}^{3}}{\mathrm{~h}}} \frac{(0.05 \mathrm{~m})^{2}}{0.07 \mathrm{~m}}\right)=1.6266 \mathrm{~h}
\end{gathered}
$$

The temporal behavior of the interior wall temperature that occurs when there is a $10^{\circ} \mathrm{C}$ increase in the exterior temperature is shown in Figure 2, while Figure 3 shows the behavior of the interior wall temperature when the Outside temperature oscillates sinusoidally with a frequency of $0.26180 \mathrm{~h}-1$ and an amplitude of $5^{\circ} \mathrm{C}$.

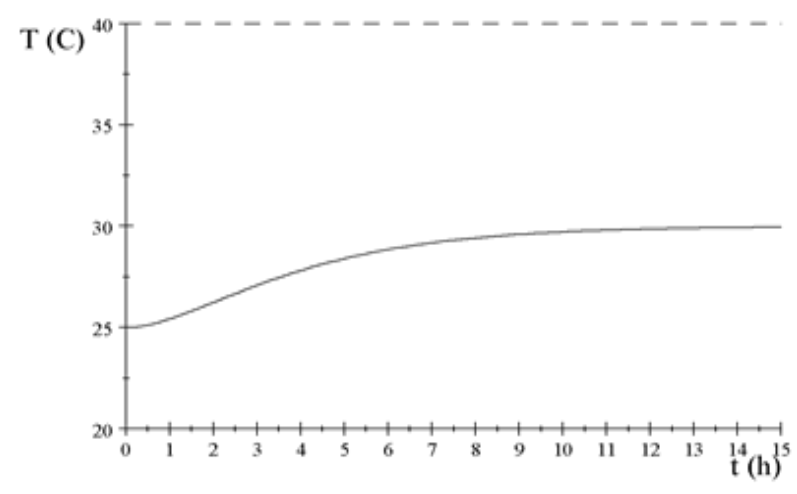

Figure 2. The behavior of the interior wall temperature (solid line) when the exterior temperature increases by 10 degrees (dashed line)

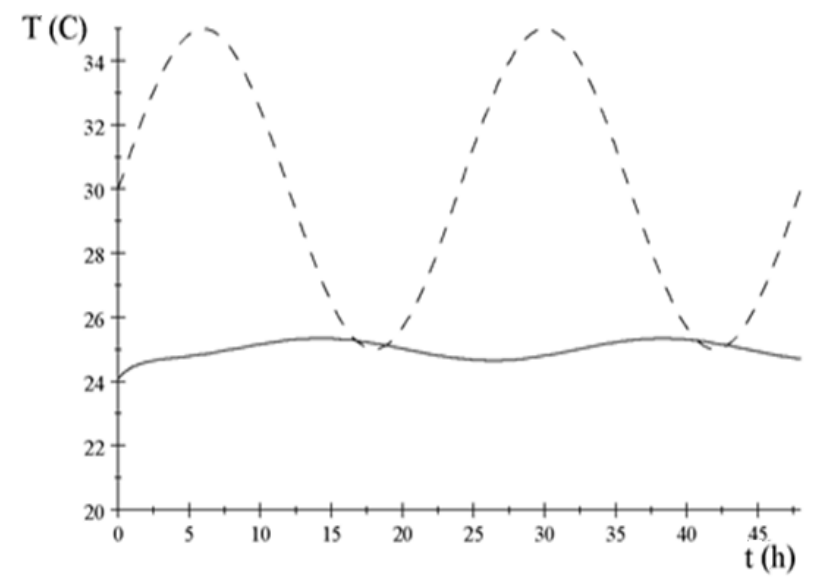

Figure 3. The behavior of the interior wall temperature (solid line) when the exterior temperature fluctuates throughout the day (dashed line)

\section{Possible energy consumed}

For an approximation of the possible energy consumed, a tower cooling system was considered, which works by pumping water in a flow to obtain an internal temperature of $25^{\circ} \mathrm{C}$. The pumping system consumes $400 \mathrm{~W} . \mathrm{h}$ in continuous work while the global cooling system, for a similar system, is equivalent to $100 \mathrm{~W} . \mathrm{h}$. The energy consumption is obtained directly from the electricity required for the operation of both types of equipment. However, it is necessary to consider the costs of creating the cooling systems. 
While a standard air conditioning system ranges between $\$ 400.00$ to USD $1,000.00$ depending on the type and brand, the development of the cooling system will surely have a higher cost for the piping arrangement used, as well as the cooling tower to be located in a strategic section on the roof of the building, however, it may have higher life systems. Furthermore, the pumping system could use alternative energy such as solar or wind, which would also reduce global emissions in energy production.

In future work, it is expected to design the piping system and the associated costs, considering higher durability than traditional processes but an accessible cost for the communities with fewer resources.

\section{Conclusions}

From the application of the law of conservation of energy and the application of the principles related to heat transport, a mathematical model was obtained that allows predicting the temporal behavior of the interior temperature of the wall of a room with respect to the outdoor temperature and the temperature and flow of the water used in its internal environment and which flow considering a uniform temperature in order to maintain the comfort of a room. Although the model has been developed considering the existence of a climate, hot, extreme in such a way that the purpose of the water flow is cooling, the proposed model can be adapted for its application in low-temperature climates, wherein the interior of the structure can flow high-temperature water compared to the outside temperature. In this sense, the model can be used to consider the most appropriate water flow and temperature to reduce the costs of this system and compare these with those related to the use of conventional air conditioning equipment.

In future work, the external system will be designed that can maintain the water at temperature.

\section{Acknowledgements}

This work was partially supported by the CONACYT project National Problems 2017.

\section{REFERENCES}

[1] Griego, D., Krarti, M. \& Hernández-Guerrero, A. (2012). Optimization of energy efficiency and thermal comfort measures for residential buildings in Salamanca, Mexico. Energy and buildings, 54, 540-549.

[2] Liu, F., Meyer, A., S. \& Hogan, J., F. (2010). Mainstreaming building energy efficiency codes in developing countries. Global experiences and lessons from early adopters.
Washington, DC: The International Bank for Reconstruction and Development, The World Bank.

[3] Wonorahardjo, S., Sutjahja, I. M., Mardiyati, Y., Andoni, H., Thomas, D., Achsani, R. A., \& Steven, S. (2020). Characterising thermal behaviour of buildings and its effect on urban heat island in tropical areas. International Journal of Energy and Environmental Engineering, 11(1), 129-142

[4] André, C., Jonathan, M., César, L., \& Carlos, H. (2019). Use of Renewable Energies in Sustainable Facilities for Rural Housing Module. In MATEC Web of Conferences (Vol. 303, p. 02002). EDP Sciences

[5] Huelsz, G., Barrios, G., Rechtman, R., \& Rojas, J. (2009). Importancia del análisis de transferencia de calor dependiente del tiempo en la evaluación del desempeño térmico de la envolvente de una edificación. Estudios de Arquitectura Bioclimática, 11-20.

[6] Carrazco Cota, C., \& Morillón, D. (2004). Adecuación bioclimática de la vivienda de interés social del noroeste de México con base al análisis térmico de la arquitectura vernácula. Avances en Energías Renovables y Medio Ambiente, 8 .

[7] Armenta-Déu, C., Donaire, T., \& Hernando, J. (2003). Thermal analysis of a prototype to determine radiative cooling thermal balance. Renewable energy, 28(7), 1105-1120.

[8] Mayorga-Pérez, D. F., del Rocío Castro-Cepeda, L., Layedra-Larrea, N. P., Pérez-Peñafiel, B. E., \& Morales-Avilés, C. E. (2020). Determinación de la conductividad térmica y resistencia mecánica de placas conformadas de cemento y polietileno teraftalato (pet), como una alternativa de cuidado al medio ambiente. Polo del Conocimiento, 5(3), 595-618.

[9] Giraldo, J. D., \& Arango, J. P. (2020). Optimization process in the design of passive solar heating system. Revista Técnica Energía, 16(2).

[10] Morales, M. R. (2019). Cinco consideraciones en la composición arquitectónica de la vivienda social vertical en Aguascalientes por del estilo de vida actual. Labor E Engenho, 13, e019003-e019003.

[11] Molar-Orozco, M. E. (2017). Comparación del comportamiento térmico de muros de concreto armado y de bloques de concreto huecos. Legado de Arquitectura y Diseño, 12(22).

[12] Chen, Z., Zhu, L., Raman, A., Fan, S., 2016. Radiative cooling to deep sub-freezing temperatures through a 24-h day-night cycle. Nat Commun 7, 1-5. doi:10.1038/ncomms13729.

[13] Borbón, A. C., Cabanillas, R. E., \& Pérez, J. B. (2010). Modelación y simulación de la transferencia de calor en muros de bloque de concreto hueco. Información tecnológica, 21(3), 27-38.

[14] Argüello, J. C. C., Dzul, F. T., May, G. R., \& Arroyo, D. L. T. (2018). 2. Desarrollo y análisis térmico de la aplicación de techumbre verde a nivel laboratorio. AvaCient, 4(1), 20-28.

[15] Vall, S., Castell, A., Medrano, M., 2018. Energy savings potential of a novel radiative cooling and solar thermal collection concept in buildings for various world climates. 

Energy Technology
6, 2200-2209. doi:
$18-22$.

$10.1002 /$ ente. 201800164

[16] Suárez-Domínguez, E. J., Aranda-Jiménez, Y. G., Fuentes-Pérez, C., \& Zúñiga-Leal, C. (2017). Behavior of the heat capacity and ultrasonic characterisation for poured earth. Journal of Mechanical and Civil Engineering, 14(6),
[17] Suárez-Domínguez, E. J., Aranda-Jiménez, Y. G., Palacio-Pérez, A., Rodríguez-Valdés, A., \& Izquierdo-Kulich, E. (2015). Oscillating temperature profile model for a poured earth wall. Concreto y cemento. Investigación y desarrollo, 7(1), 44-51. 